\title{
Diretrizes para a implementação de fluxo contínuo em obras de edificações
}

\author{
Guidelines for implementing continuous flow in building \\ projects
}

\author{
lamara Rossi Bulhões \\ Flávio Augusto Picchi
}

\section{Resumo}

$\Delta$

variabilidade na produção e a falta de sincronização entre os processos são dois importantes fatores que podem provocar as interrupções no fluxo de trabalho, aumentando a parcela de atividades que não agregam valor e a quantidade de estoques de produtos inacabados. A aplicação do princípio do fluxo contínuo na manufatura busca eliminar esses estoques através da produção unitária, sem interrupção entre os diversos subprocessos produtivos. O presente trabalho investiga a aplicação do fluxo contínuo no ambiente da construção civil. Seu objetivo principal é propor diretrizes para a implementação de fluxo contínuo na construção civil, com base nos conceitos e ferramentas da Mentalidade Enxuta (ME). A estratégia de pesquisa adotada foi a pesquisa-ação, sendo realizados dois estudos empíricos em obras de edificações. Entre as contribuições desta pesquisa destaca-se um conjunto de diretrizes para implementar fluxo contínuo, vinculadas às etapas de diagnóstico, criação de condições iniciais, e Planejamento e Controle da Produção (PCP). Através destas diretrizes propõe-se o uso combinado das ferramentas tradicionais da ME com ferramentas de PCP adequadas ao ambiente da construção civil.

Palavras-chave: Mentalidade enxuta. Fluxo contínuo. Redução do lote. Aumento da estabilidade.

lamara Rossi Bulhões Programa de Pós-Graduação da Engenharia da Produção Universidade Federal do Rio Grande do Sul Av. Osvaldo Aranha, 99, $5^{\circ}$ andar Porto Alegre - RS - Brasi CEP 90035-190 Tel.: (51) 3308-4299 E-mail: iamara@producao.ufrgs.br

Flávio Augusto Picchi Lean Institute Brasil Rua Topázio, 911 São Paulo - SP - Brasil CEP 04105-063

Tel. : (11) 5571-6887

E-mail: fpicchi@lean.org.br

Recebido em 17/10/11

Aceito em 29/12/11

\section{Abstract}

The variability in production and the lack of synchronization between processes are two important factors that cause interruptions in workflows, increasing the share of unproductive time and the amount of work in progress. The application of the principle of continuous flow in manufacturing aims to eliminate work in progress through the implementation the one peace flow, without interruption between production processes. This research work investigates the use of the continuous flow principle in the context of the construction industry. It aims to propose guidelines for the implementation of continuous flow in the construction industry, based on the Lean Thinking concepts and tools. Action research was the research strategy adopted in this study, which involved the development of two empirical studies in building projects. The main contributions of this study is a set of guidelines for implementing continuous flow which are concerned with the stages of diagnosis, establishment of the initial conditions, and production planning and control. Those guidelines, suggest the combined use of traditional Lean Thinking tools and planning and control tools that are suitable for the construction context.

Keywords: Lean Thinking, continuous flow, small batch, increasing stability. 


\section{Introdução}

Existe um crescente interesse tanto por parte da indústria como por parte da academia na aplicação de conceitos e princípios do paradigma da Mentalidade Enxuta (ME) para melhorar a gestão da produção na construção civil, em função da sua ênfase a eliminação de perdas, incluindo os estoques da produção. Um dos princípios fundamentais da $\mathrm{ME}$ diz respeito à implementação de fluxo contínuo nos processos de produção, que significa produzir uma peça de cada vez sem interrupção entre estes, ou seja, sem geração estoque. (WOMACK; JONES, 1996; ROTHER; SHOOK, 1999). Contudo, as interrupções no fluxo de trabalho são bastante comuns não só na construção civil (KOSKELA, 1992), mas também em outras indústrias de manufatura (LIKER, 2004). Segundo Takahashi e Osada (1993), isso ocorre por vários motivos, entre os quais: variações da capacidade de produção nos postos de trabalho, longo tempo de setup, desequilíbrio entre as cargas de trabalhos de dois processos consecutivos, ocorrência de defeitos de qualidade e quebra de equipamentos.

Com freqüência, para reduzir o impacto desses problemas na produção, mantêm-se grandes estoques, principalmente os estoques em processo (work-in-progress). Como os sistemas de produção são instáveis, com elevada variabilidade e com falhas na gestão de recursos, são necessários estoques para proteger a produção, os quais escondem os problemas que deveriam aparecer para serem resolvidos (HOPP; SPEARMAN, 1996).

Uma possível estratégia para reduzir estoques é a aplicação do princípio do fluxo contínuo, que é apontado como um mecanismo indutor de melhoria de todo o sistema de produção. De fato, Liker (2004) apresenta alguns benefícios decorrentes da implementação do fluxo contínuo: criação de flexibilidade real, aumento da produtividade, identificação de pontos de ociosidade e sobrecarga de trabalho no sistema, liberação de espaço e redução do custo de estoques.

$\mathrm{Na}$ construção civil existem alguns trabalhos que chamam a atenção sobre a necessidade de se gerenciar os fluxos de produção nos canteiros de obras (KOSKELA, 1992; 2000; SANTOS, 1999). Contudo, existe neste setor um inadequado entendimento da natureza destes fluxos (KOSKELA, 1992), em parte porque alguns dos conceitos envolvidos na implementação do fluxo contínuo na manufatura necessitam de adaptações.
O objetivo deste trabalho é propor um conjunto de diretrizes para a implementação do fluxo contínuo na construção civil. Essas diretrizes estão baseadas nos princípios básicos da ME e sugerem o uso combinado de ferramentas tradicionais da ME com ferramentas de Planejamento e Controle da Produção (PCP) usadas na construção civil.

\section{Conceitos fundamentais relacionados ao fluxo contínuo}

Conforme definido acima, o fluxo contínuo é a produção apenas do que é exigido pelo processo seguinte, ou cliente final, sem geração de estoque (ROTHER; SHOOK,1999). O impacto imediato da implementação do fluxo contínuo é a redução o lead time, ou seja, o intervalo de tempo entre a entrada da matéria-prima até a saída dos produtos acabados. A retirada do estoque de produção é fundamental para que os problemas de produção sejam explicitados e resolvidos (LIKER, 2004; WOMACK; JONES, 1996).

Além da necessidade de eliminar (ou reduzir) os estoques, existem outros conceitos importantes relacionados ao fluxo continuo, como por exemplo, velocidade de produção e estabilidade. A velocidade de produção é a taxa com que os produtos devem ser entregues aos clientes no tempo solicitado, devendo a mesma ser definida pelo tempo takt, o tempo disponível para atender a uma determinada demanda por parte do cliente (ALVAREZ; ANTUNES JÚNIOR, 2001).

A estabilidade é apontada como um pré-requisito para iniciar a implementação dos princípios da ME (SMALLEY, 2005). Há na bibliografia recomendações sobre como obter estabilidade, mas não há consenso sobre o seu significado. Smalley (2005) define estabilidade básica como a previsibilidade geral e disponibilidade constante em relação à mão-de-obra, aos materiais, às maquinas e aos métodos, denominados pelo autor de 4M's. O mesmo autor sugere que, além da disponibilidade dos recursos, estes devem ser adequados às necessidades dos processos. Por exemplo, em relação à mão-de-obra, não basta disponibilizar o número de trabalhadores necessários - estes devem ser capacitados. De forma similar Smalley (2005) sugere também que as máquinas tenham a capacidade instalada real suficientes apenas para suprir a demanda e que exista um eficiente sistema de gestão cadeia de fornecedores de forma que garanta a confiabilidade de entrega e qualidade dos materiais. 
Liker e Meier (2007), por sua vez, definem estabilidade como a capacidade de produzir resultados coerentes e sistemáticos ao longo do tempo, e a relacionam à melhoria contínua. Em um estudo empírico na produção de peças préfabricadas de concreto, Samaniego (2007) relaciona a estabilidade à quantidade de vezes que os processos seguem parâmetros pré-definidos, tais como a seqüência planejada e pouca variação nos tempos.

Na construção civil o conceito de estabilidade é utilizado por Ballard e Howell (1998) para descrever o impacto da implementação do Sistema Last Planner em empreendimentos de construção, principalmente nos níveis de médio e curto prazos. No médio prazo são identificadas e removidas restrições e o curto prazo tem o papel de atribuir pacotes de trabalho às equipes envolvidas diretamente na execução da obra, por meio de um processo participativo e sistemático (BALLARD; HOWELL, 1998; BALLARD, 1997). Em comparação aos 4M's (SMALLEY, 2005), no Last Planner o plano de médio prazo enfatiza a necessidade de gerenciar vários tipos fluxos à montante da produção, similar aos 4M's propostos por Smalley (2005), além de outros que são típicos da construção civil, tais como espaço, projeto, e instalações provisórias.

Em relação à redução da variabilidade, Liker e Meier (2007) apontam que a falta de estabilidade é resultado da variabilidade de processos. Smalley (2005) enfatiza a necessidade do trabalho padronizado para alcançar a estabilidade básica, no qual devem ser estabelecidos procedimentos precisos (altamente detalhados) para o trabalho dos operadores (MONDEN, 1993; SPEAR; BOWEN, 1999).

No Last Planner existem mecanismos para conviver com a variabilidade inerente ao contexto da construção civil, incluindo o mecanismo de proteção da produção (shielding production) através dos seguintes processos:

(a) criação de uma janela de confiabilidade no horizonte de curto prazo, através da programação, apenas, de pacotes de trabalho que tenham todas as suas restrições removidas; e

(b) estabelecimento de pacotes de trabalho suplentes (tarefas reserva) no horizonte de curto prazo, com todas as restrições removidas, caso ocorram problemas no decorrer da semana que não podem ser previstos anteriormente.

Com relação à melhoria contínua, o Last Planner possui mecanismos eficazes para implementá-la, por meio de mecanismos de participação, estabelecimento de curtos ciclos de controle e a medição de desempenho (BALLARD; HOWELL, 1998).

\section{Ferramentas para implementação de fluxo contínuo}

Para implementação do fluxo contínuo, Rother e Shook (1999) e Rother e Harris (2002) propõem a seguinte seqüência de aplicação de ferramentas:

(a) elaboração de um mapa do estado atual do sistema de produção;

(b) identificação, a partir deste mapa, dos processos que apresentam potencial de implementação de fluxo contínuo;

(c) proposição do mapa de estado futuro no qual se pode obter fluxo contínuo com base nas oportunidades de melhoria identificadas;

(d) detalhamento do processo, mudando para uma perspectiva mais operacional, por meio do Gráfico de Balanceamento do Operador; e

(e) elaboração da Tabela do Trabalho Padronizado Combinado.

A seguir, é apresentada uma breve descrição de cada uma dessas ferramentas (ROTHER; SHOOK, 1999; ROTHER; HARRIS, 2002):

(a) Mapa do Fluxo de Valor (MFV): seu objetivo é identificar a ocorrência de desperdícios e tentar eliminá-los por meio de um projeto do sistema de produção, ou seja, um estado futuro do sistema, no qual se adote o fluxo contínuo e a produção puxada. Neste mapa são representadas todas as etapas envolvidas nos fluxos de material e informação, necessárias para atender aos clientes, desde o pedido até a entrega;

(b) Gráfico de Balanceamento do Operador (GBO): após o MFV faz-se uma investigação detalhada dos processos para balancear (igualar o tempo de processamento) e otimizar o tempo do operador. Para essa investigação usa-se o GBO, ferramenta que auxilia na distribuição do trabalho dos operadores em relação ao tempo takt. A elaboração do GBO é composta por algumas etapas como: identificação dos elementos do trabalho ${ }^{1}$; eliminação do trabalho desnecessário (operações e processos que não agregam valor); medição dos tempos de cada elemento de trabalho com cronômetros; e distribuição do trabalho.

(c) Tabela de Trabalho Padronizado Combinado (TTPC): é elaborada após o GBO, na qual se tem um desenho de operações mais detalhado. A

\footnotetext{
${ }^{1}$ Definido como o menor incremento de trabalho que pode ser
} transferido para uma outra pessoa (LEAN..., 2003). 
principal diferença entre esta e o GBO é a interação entre os diferentes operadores.

Além das ferramentas apresentadas acima, no presente trabalho adotou-se a Linha de Balanço (LB) no planejamento de longo prazo. Existe uma bibliografia bastante ampla sobre esta técnica (ARDITI; ALBULAK, 1986; PRADO, 2002), mas só recentemente a sua aplicação passou a ser discutida pela comunidade acadêmica interessada na Produção Enxuta (SEPPÄNEN; KANKAINEN, 2004). Entre os conceitos relacionados ao fluxo contínuo explicitamente utilizados na LB, destacam-se o tamanho do lote, tempo de ciclo e ritmo de processos (BULHÕES; FORMOSO, 2004; SCHRAMM; RODRIGUES; FORMOSO, 2006).

\section{Método de pesquisa}

A estratégia de pesquisa adotada foi a pesquisaação, definida por Thiollent (2005) como um tipo específico de pesquisa com base empírica que é concebida e realizada por meio de uma ação em que os pesquisadores e algumas pessoas participantes da situação ou do problema estão envolvidos de modo cooperativo. A realização da pesquisa-ação foi justificada principalmente pela necessidade de realizar intervenções em organizações para propor diretrizes para implementar fluxo contínuo em obras, a partir da abstração de conceitos que são utilizados na manufatura e a sua adaptação para a construção civil.

Foram realizados dois estudos empíricos, em duas obras distintas, executadas por diferentes empresas. O primeiro estudo, realizado na obra A teve como objetivo compreender os principais elementos do fluxo contínuo no contexto de obras de edificações e identificar os requisitos necessários para a sua implementação. O segundo estudo, realizado na obra B teve como objetivo investigar a estabilidade básica, considerada, no trabalho, como um pré-requisito para a implementação de fluxo contínuo.

A obra A consistiu na construção de um hotel, localizado em Natal-RN, com cerca de $20.000 \mathrm{~m}^{2}$ de área construída, 397 apartamentos localizados em sete pavimentos, distribuídos em nove blocos distintos (A, B, C, D, E, F, G, H e I). A obra tinha o prazo de execução de dezessete meses e a mãode-obra era toda sub-contratada.

A partir da revisão bibliográfica e observações iniciais em obra, foram formuladas as seguintes proposições de pesquisa:

(a) utilização da Linha de Balanço como técnica de planejamento de longo prazo, por enfatizar a determinação do seqüenciamento e dos ritmos dos processos-chave, considerados como elementos fundamentais para o estabelecimento de um tempo takt para a obra; e

(b) aplicação das ferramentas MFV, GBO e TTPC para elaboração de uma proposta de implementação do fluxo contínuo.

$\mathrm{O}$ trabalho foi divido em três etapas. Na primeira etapa, denominada de diagnóstico, foi realizado uma análise do sistema de produção e elaborado o plano de longo prazo do empreendimento. Ainda nesta fase, usaram-se o MFV do apartamento padrão para auxiliar a identificação de alguns problemas da produção, principalmente os relacionados ao trabalho em progresso. $\mathrm{Na}$ segunda etapa, denominada de proposta de implementação do fluxo contínuo, foram selecionados os processos que poderiam ocorrer em fluxo contínuo, e elaborados os mapas de fluxo de valor por processo, o GBO e a TTPC. Na terceira etapa foram feitas as análises dos dados, sendo os resultados posteriormente discutidos com a direção da empresa. Em função problemas relacionados à disponibilidade de recursos na obra, a proposta de melhoria não foi implementada pela empresa, que optou por alterar o sistema de PCP, visando a obter estabilidade básica.

As etapas 2 e 3 caracterizaram-se pela permanência da pesquisadora na obra (num período de oito dias) e pela realização de sucessivas reuniões entre pesquisadora, gerente de contrato e engenheira de planejamento. Além desses intervenientes, foram envolvidos nas decisões o representante do cliente e o diretor de suprimentos.

A obra B tratava-se de um condomínio horizontal, na cidade de Campinas - SP, formado por 59 casas. A obra teve o prazo de vinte meses, sendo que a mão-de-obra era totalmente subcontratada. Ao longo da pesquisa foram estabelecidas proposições relacionadas ao uso do sistema Last Planner (BALLARD; HOWELL, 1998) como forma de obtenção da estabilidade básica.

$\mathrm{O}$ trabalho foi dividido em três etapas. A primeira etapa, denominada de diagnóstico, iniciou-se por uma reunião com os principais envolvidos na gestão da obra (engenheiro da obra, assistente técnico e mestre de obra) na qual se fez uma análise do PCP existente na obra. Neste período fez-se, também, um estudo dos tempos de ciclos dos processos produtivos em execução na obra. $\mathrm{Na}$ segunda etapa, denominada de melhorias no PCP, optou-se por focar os trabalhos na melhoria do sistema de PCP, com base no Sistema Last Planner para obtenção da estabilidade básica, ao invés de propor diretamente a implementação do 
fluxo contínuo. Nesta etapa foram implementados os níveis de planejamento de médio e curto prazos, adotando-se a LB como plano de longo prazo. A LB foi elaborada em conjunto por um dos pesquisadores, o assistente técnico e o mestre de obras. Nesse processo foram introduzidos alguns conceitos de ME, tais como a redução do tempo de ciclo e identificação de processos que poderiam ocorrer em fluxo contínuo. Na terceira etapa foram feitas as análises dos dados e posteriormente os resultados foram apresentados e discutidos com representantes da empresa. As etapas 1 e 2 ocorreram ao longo de oito meses, sendo a principal fonte de evidência a participação da pesquisadora em reuniões de curto e médio prazo ao longo deste período.

Houve algumas importantes conexões entre os dois estudos empíricos. O estudo empírico 1 permitiu a compreensão dos principais elementos do fluxo contínuo e os requisitos para a sua implementação, contribuindo para a estruturação do estudo 2, cujo foco foi a compreensão do papel do PCP na criação da estabilidade básica.

\section{Resultados dos estudos}

\section{Estudo empírico 1}

\section{Diagnóstico, elaboração do novo plano de longo prazo e MFV atual}

No início deste estudo constatou-se que o plano de longo prazo existente era informatizado e excessivamente detalhado, não existindo uma hierarquização do mesmo. A versão inicial deste plano havia sido elaborada pela engenheira de planejamento, que semanalmente o atualizava e apresentava em reunião com gerência da obra e representante do cliente. A partir da atualização do plano, a engenheira fazia uma lista com as atividades que deveriam ser executadas na semana. Entre os problemas observados no PCP, destacamse os seguintes:

(a) falta de programação de recursos (materiais, equipamentos e mão de obra) vinculada ao PCP;

(b) falta de definição do seqüenciamento de execução das atividades; e

(c) grande quantidade de estoque em processo; e

(d) atrasos na entrega dos projetos executivos, os quais eram elaborados na própria obra por uma equipe de projeto local.

A partir destes problemas, decidiu-se utilizar a LB para o planejamento de longo prazo. No 0 estão apresentadas algumas informações utilizadas para gerar a LB, cujos dados foram definidos em uma reunião envolvendo a pesquisadora, a engenheira de planejamento e o sub-empreiteiro de divisórias de gesso acartonado (dry wall), com base na experiência de obras anteriores.

Em função da obra estar na fase de estrutura, não havia representantes de outras equipes para participar da discussão dos ritmos adotados na LB. A partir dessas informações, elaborou-se a LB apresentada na 0 , para um dos blocos do empreendimento.

\begin{tabular}{|l|c|c|c|}
\hline $\begin{array}{c}\text { Seqüenciamento dos } \\
\text { processos }\end{array}$ & $\begin{array}{c}\text { Número de } \\
\text { equipes }\end{array}$ & $\begin{array}{c}\text { Ritmo } \\
\text { (apartamento/dia) }\end{array}$ & $\begin{array}{c}\text { Produtividade estimada } \\
\text { (hh/apartamento) }\end{array}$ \\
\hline 1 Vedação parcial & 1 & 4 & 2,2 \\
\hline 2 Marcação & 1 & 4 & 2,2 \\
\hline 3 Dry wall 1 & 2 & 4 & 4,4 \\
\hline 4 Instalação 1 & 2 & 4 & 4,4 \\
\hline 5 Dry wall 2 & 2 & 4 & 4,4 \\
\hline 6 Impermeabilização & 1 & 4 & 2,2 \\
\hline 7 Assentamento \\
cerâmico
\end{tabular}

Quadro 1 - Informações utilizadas para gerar a LB 


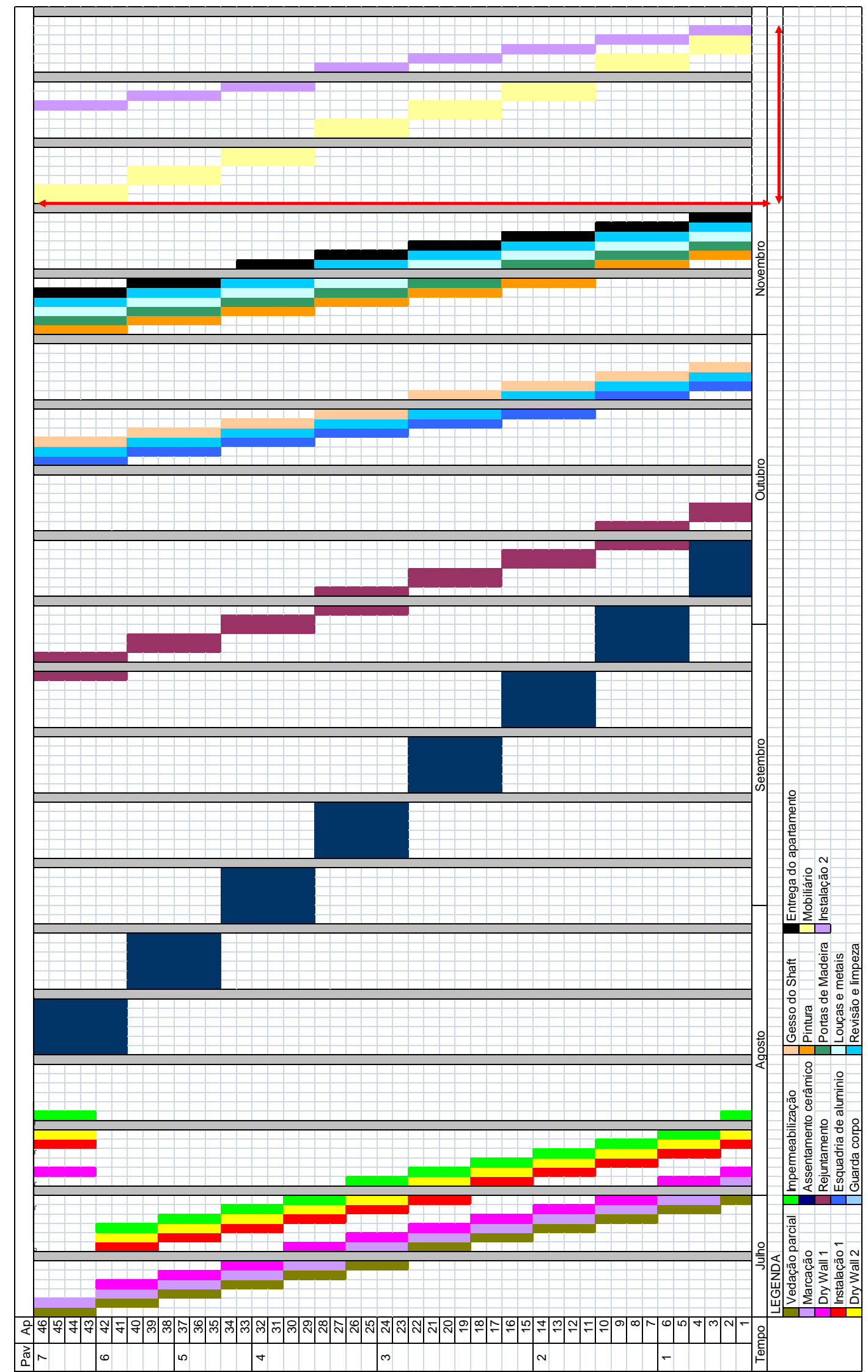

Figura 1 - Extrato da LB 


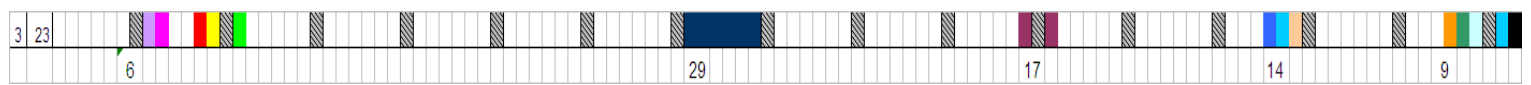

Figura 2 - Linha correspondente ao apartamento 23 da LB com os respectivos tempos, em dias

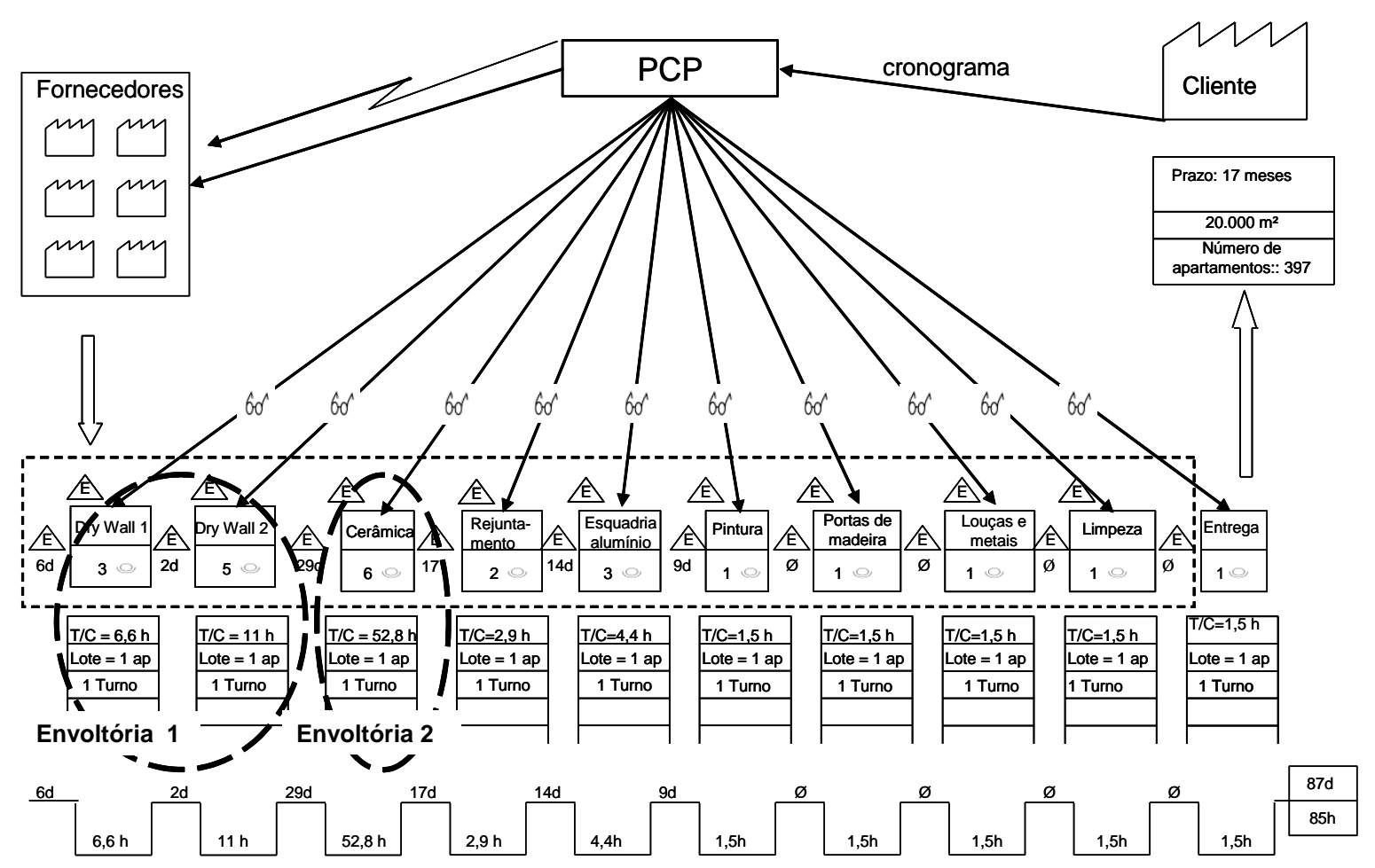

Figura 3 - MFV atual do apartamento

Na LB (0) estão apresentados o seqüenciamento e os ritmos planejados dos principais processos envolvidos na execução do apartamento padrão, e buscou-se, também, incorporar algumas melhorias em relação ao plano de longo prazo existente, tais como:

(a) redução do tamanho do lote, por meio da divisão das zonas de trabalho por apartamentos, ao invés de pavimentos;

(b) sincronização ${ }^{2}$ dos diferentes sub-processos do dry wall, ao contrário da prática corrente de se dar um ritmo maior aos sub-processos iniciais (normalmente instalação de montantes). Esta sincronização foi obtida por meio de um redimensionamento das equipes;

(c) introdução de folga planejada entre os subprocessos dry wall 1 e instalação 1 , em função de problemas de projeto; e

(d) busca pela redução de estoques em processo.

Porém, conforme observado na 0 , houve limitações na implementação destas melhorias. Observam-se,

\footnotetext{
${ }^{2}$ Significa alcançar continuidade no fluxo de materiais (produtos) entre as estações de trabalho através da retirada do estoque em processo (BLACK, 1998)
}

por exemplo, períodos em que não ocorrem quaisquer atividades, principalmente em função dos processos terem ritmos diferentes e da postura por parte da gerência da obra de utilizar grandes estoques e folgas para evitar interrupções e interferências entre as equipes.

Após a elaboração da LB, passou-se para a elaboração do MFV atual do apartamento padrão, com a representação dos principais processos envolvidos na sua execução. Os processos analisados no mapa foram obtidos diretamente da LB. Porém, visando a reduzir o número de processos, algumas mudanças no agrupamento das atividades foram feitas:

(a) marcação e dry wall 1 (redenominado dry wall 1);

(b) instalação 1, dry wall 2 e impermeabilização (redenominado dry wall 2); e

(c) esquadria de alumínio, guarda-corpo e gesso do shaft (redenominado esquadria de alumínio).

Os estoques entre processos foram extraídos também da LB, considerando-se as folgas na execução do apartamento $23(0)$, ou seja, a posição média na LB, que tinha 46 apartamentos). 
Na 0 está apresentado o MFV atual do apartamento padrão. Os fornecedores estão representados pela caixa à esquerda do mapa, na qual existem várias empresas responsáveis pelo suprimento de matéria-prima para a obra. Do outro lado do mapa estão as informações relacionadas ao cliente. Considerou-se como cliente a organização que paga os processos concluídos mediante medições semanais. A definição da quantidade de serviços a ser executado por mês foi estabelecida a partir do cronograma físico do empreendimento.

O fluxo de informação está representado na parte de cima do MFV, através do processo de PCP, no qual são planejados os diferentes processos de forma independente. Estes planos eram baseados nas metas estabelecidas pelo cronograma físico e semanalmente eram feitas avaliações in loco do que realmente foi executado, sendo normalmente necessária sua reprogramação. A linha de tempo, desenhada abaixo das caixas de dados (0), registra o lead time de produção (LTP) e o tempo de agregação de valor (TAV), 87 dias e 85 horas, respectivamente. Esse resultado indica que apenas $11 \%$ do tempo gasto para se entregar um apartamento agrega valor ao cliente final, sendo que os outros $89 \%$ podem ser considerados como desperdícios.

\section{Proposta de implementação de fluxo contínuo}

A partir da LB e do MFV foram escolhidos os processos de dry wall e revestimento cerâmico (demarcados pelas envoltórias 1 e 2 na 0) para planejar a implementação de fluxo contínuo. Essa escolha foi em função da importância destas atividades para o andamento da obra e pelo fato de que este serviço estava sendo analisado pela equipe gerencial visando à contratação do subempreiteiro. Como ainda não havia funcionários executando o dry wall, não foi possível elaborar o GBO e a TTCP, sendo que o estudo referente a este serviço limitou-se ao diagnóstico do processo atual através da elaboração do MFV (0), e a proposta do seu estado futuro, como um plano de melhoria. Com relação ao revestimento cerâmico, este estava sendo executado no apartamento modelo no período da coleta de dados, o que possibilitou o estudo detalhado desse processo, bem como o envolvimento dos funcionários na elaboração do GBO e do TTCP.

O mapa permitiu analisar mais detalhadamente este processo, que foi sub-dividido em quatro subprocessos (dry wall 1 e 2, marcação e instalação). No mapa foram observados que o tempo de ciclo (T/C) da marcação foi de $2,2 \mathrm{~h}$ e dos demais processos foram de 4,4 h. Esses dados foram obtidos da LB. A espera que existe é de 2 dias entre o dry wall 1 e as instalações. O TAV é de 15,4 h e o LTP é de 3,8 dias.

Para a elaboração do MFV futuro (0), utilizou-se o roteiro sugerido por Rother e Shook (1999).

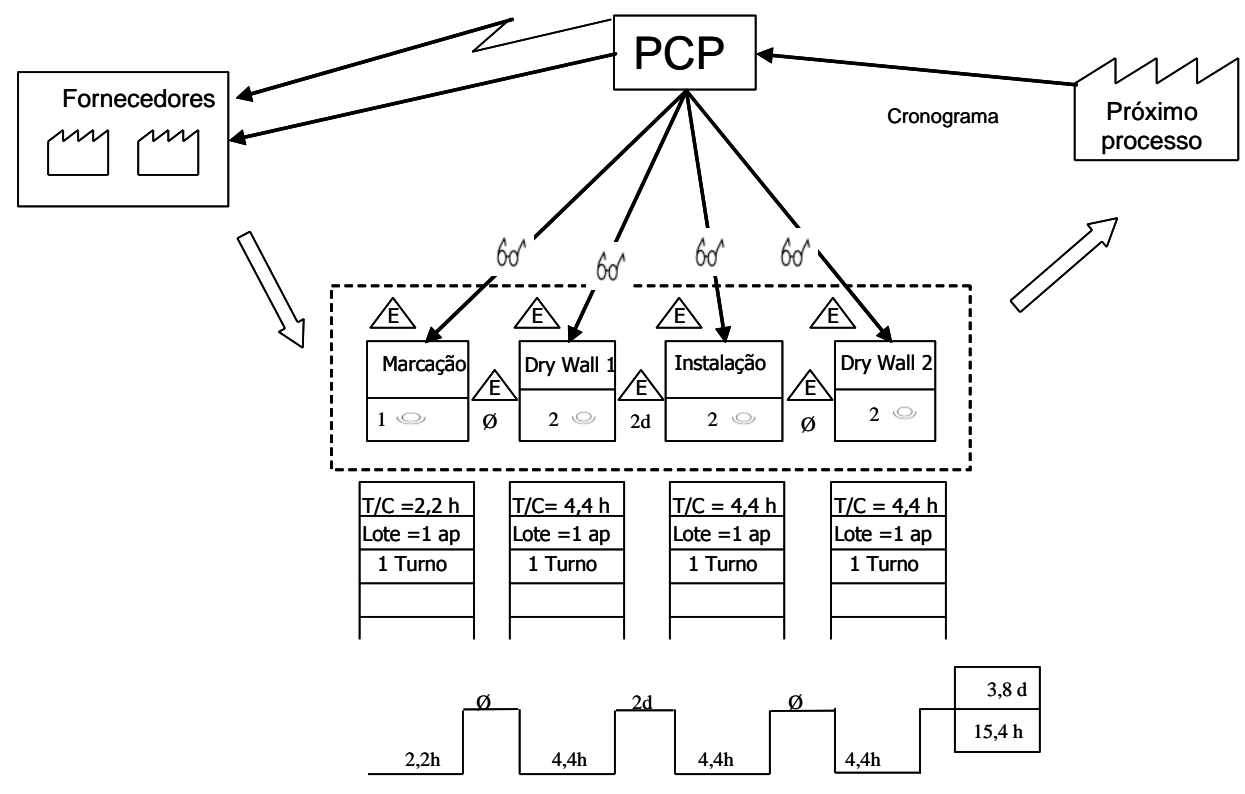

Figura 4 - MFV atual do dry wall 


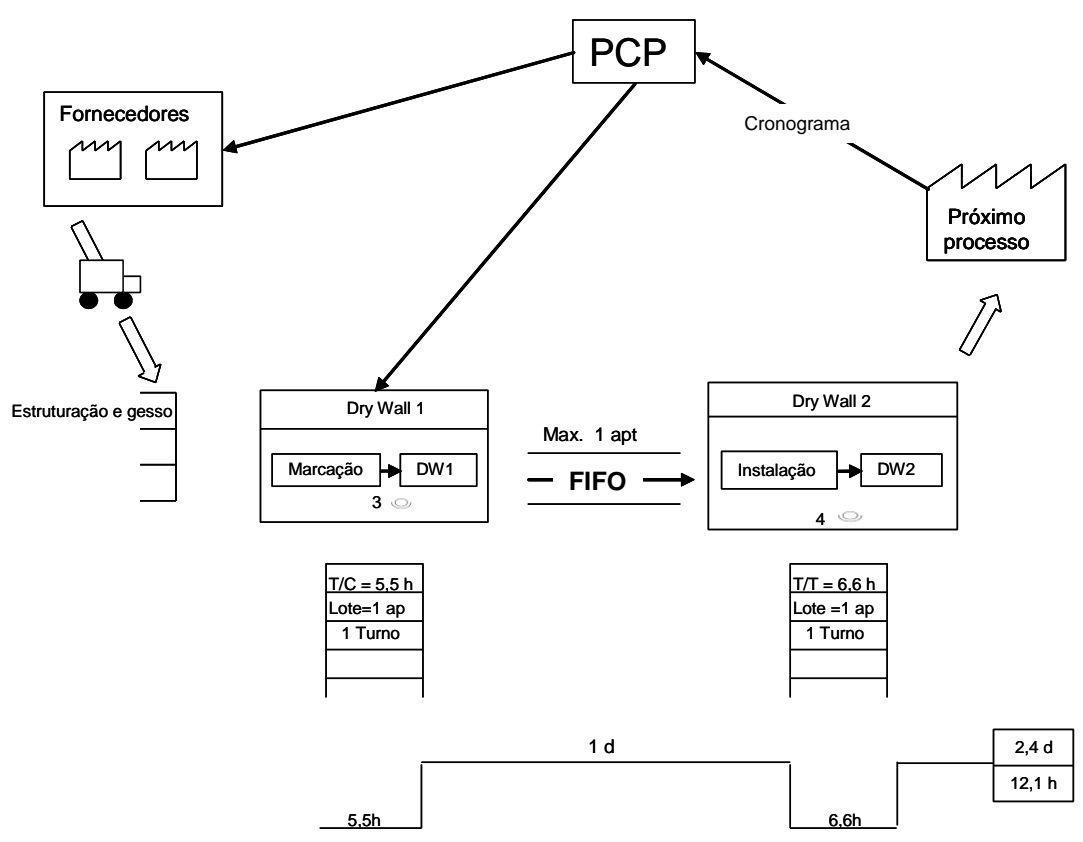

Figura 5 - Mapa do estado futuro do processo de dry wall

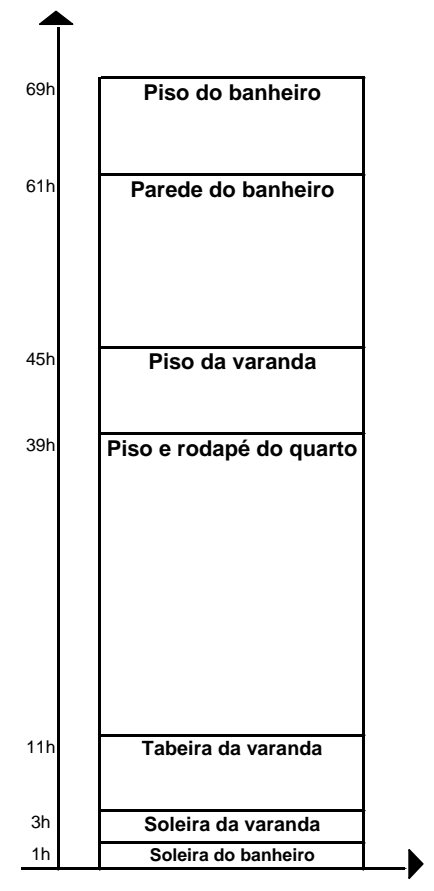

(a)

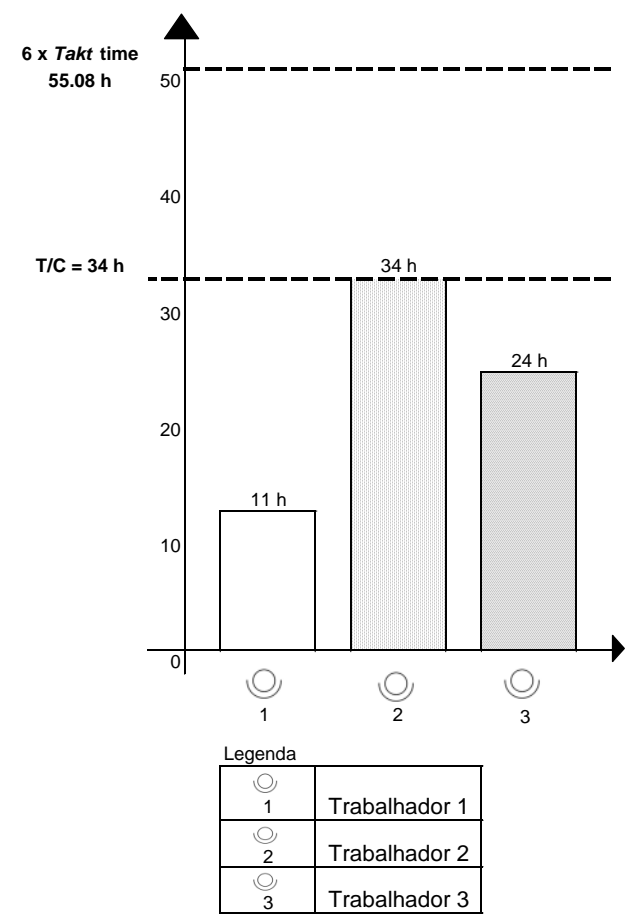

(b)

Figura 6 - Conteúdo do Trabalho (a) e Gráfico do Balanceamento do Operador (b)

Foram propostas duas equipes de trabalho com dois processos cada. Diminuiu-se o tamanho do lote de transferência entre a marcação e o dry wall 1 de 1 para $1 / 2$ apartamento, reduzindo-se o TAV de $15,4 \mathrm{~h}$ para 12,1h. Foi proposto também um estoque do tipo supermercado ${ }^{3}$ tipo seqüencial entre as células com estoque controlado de, no máximo, um apartamento. Esse estoque não poderia ser eliminado devido e a falhas de execução, detectadas no processo de marcação, e à

\footnotetext{
${ }^{3}$ Estoque controlado de peças, no qual é armazenada uma quantidade controlada de cada item produzido.
} 
necessidade de modificações no projeto de instalações hidráulicas,. Para a execução dessas modificações, necessitava-se de um período de aproximadamente 1 dia. Propôs-se também o uso de um estoque tipo supermercado entre o processo de dry wall 1 e o fornecedor, para reduzir o estoque de matérias-primas. Assim, o LTP final ficou em 2,4 dias, cerca de $63 \%$ do LTP no MFV atual (0).

Foi elaborado o GBO para o processo de assentamento cerâmico e iniciou-se pela análise detalhada do processo, a fim de balancear o trabalho da equipe e reduzir o tempo de ciclo. A 0 apresenta o conteúdo do trabalho e o GBO do processo, indicando o tempo takt (TT) estabelecido e o T/C de cada conjunto de operações, com base na divisão do trabalho observada na obra.

O principal papel do GBO foi comparar as durações do conjunto de operações de cada trabalhador e, também, o tempo de ciclo com o tempo takt. O TT foi calculado dividindo-se o tempo disponível total $\left(48 \operatorname{dias}^{4} \times 8.8 \mathrm{~h}=422.4 \mathrm{~h}\right)$ pelo número dos apartamentos (46 unidades), obtendo-se $9,18 \mathrm{~h}$, considerando 6 equipes. Isto significa que o tempo disponível para cada equipe executar a cerâmica de um apartamento é de 55,08 h $(6 \times 9,18$ h). As informações referentes aos tempos de processamento foram fornecidas pelos encarregados de produção, com base na execução do assentamento cerâmico do apartamento modelo. Estimava-se a realização da tarefa em 69 h (0 (a)), considerando a soma total das durações de operações, como se um apartamento fosse feito por apenas um trabalhador.

Com base na 0 , podem ser apontados os seguintes problemas:

(a) a divisão do trabalho entre trabalhadores é desequilibrada, uma vez que um trabalhador fica ocupado $34 \mathrm{~h}$ e outro apenas $11 \mathrm{~h}$; e

(b) o tempo de ciclo real (34h) é muito menor do que o tempo takt $(55,08 \mathrm{~h})$ e menor que o tempo de ciclo planejado inicialmente $(6$ dias $\times 8,8 \mathrm{~h}=$ $52,8 \mathrm{~h}$ ), indicando que o tempo alocado para realizar o trabalho foi superestimado.

No plano original da obra havia se estimado a necessidade de 18 trabalhadores. Entretanto, o número ideal de trabalhadores pode ser calculado dividindo-se o conteúdo total de trabalho (69 horas) pelo TT $(9,18 \mathrm{~h})$. Chega-se ao valor de 7,5, ou seja, para se entregar o apartamento padrão com a cerâmica concluída, necessita-se de 8 funcionários (uma aproximação de 7,5) trabalhando simultaneamente num único apartamento, ou 4 duplas trabalhando em paralelo.

A 0 apresenta um novo GBO, considerando uma distribuição balanceada das operações entre os trabalhadores. Com o trabalho balanceado entre os 3 trabalhadores da equipe, obteve-se um T/C de 24h. Com isso, percebeu-se que apenas três equipes seriam suficientes para atender à demanda definida pela LB, podendo-se reduzir o número de assentadores de 18 para 9 trabalhadores. Considerando três equipes, o tempo disponível para cada uma é de 27,5 h $(3 \times 9,18 \mathrm{~h})$, valor este que é aproximadamente $12 \%$ superior ao T/C (dentro da faixa recomendada por Rother e Harris (2002)).

Após a elaboração do GBO, a pesquisadora discutiu estes dados com os gerentes da obra, que decidiram manter a equipe de três trabalhadores e tentar reduzir o tempo de ciclo para $24 \mathrm{~h}$, de forma a reduzir, também, o número de funcionários (18 para 9). Esta discussão motivou os gerentes da obra a considerar a possibilidade de fazer alterações no plano de longo prazo, tais como reduzir a duração da execução da cerâmica, o que resultaria numa redução do TT e, conseqüentemente na redução do prazo total da obra.

A 0 apresenta o TTPC, estabelecendo as atividades que cada trabalhador deve realizar ao longo do T/C de 3 dias. Para esta tabela foi considerado um tempo de $8 \mathrm{~h}$ de trabalho por dia, sendo que $0,8 \mathrm{~h}$ foi alocada como folga adicional, em função de eventuais problemas que possam ocorrer na produção.

$\mathrm{Na} 0$ observa-se, em detalhe, o que cada funcionário deve executar em cada hora, ao longo dos três dias. Nota-se que os funcionários 1 e 2 estavam envolvidos na mesma atividade, já que a operação que requer mais homens-hora é o piso e rodapé do quarto. A TTPC pode ser utilizada para comunicar a seqüência e o ritmo de trabalho previsto, contribuindo também para monitorar a execução do processo. Isto ajuda na identificação e conseqüente resolução de problemas no posto de trabalho. Outra informação importante contida na TTPC é a explicitação do tempo takt, um dos elementos do trabalho padronizado.

\footnotetext{
${ }^{4}$ Dado extraído da LB.
} 


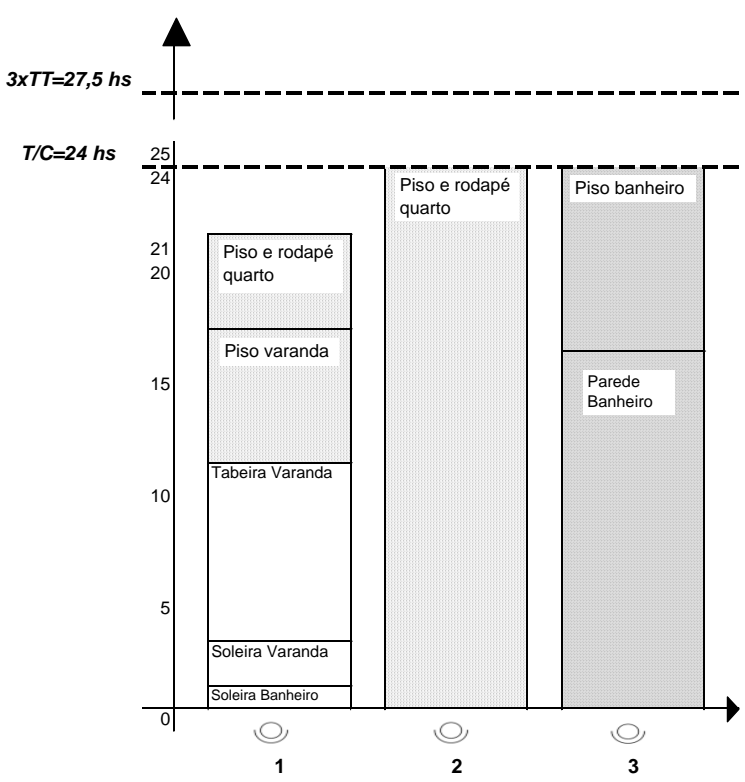

Figura 7 - Proposta de GBO considerando a necessidade de balanceamento da equipe

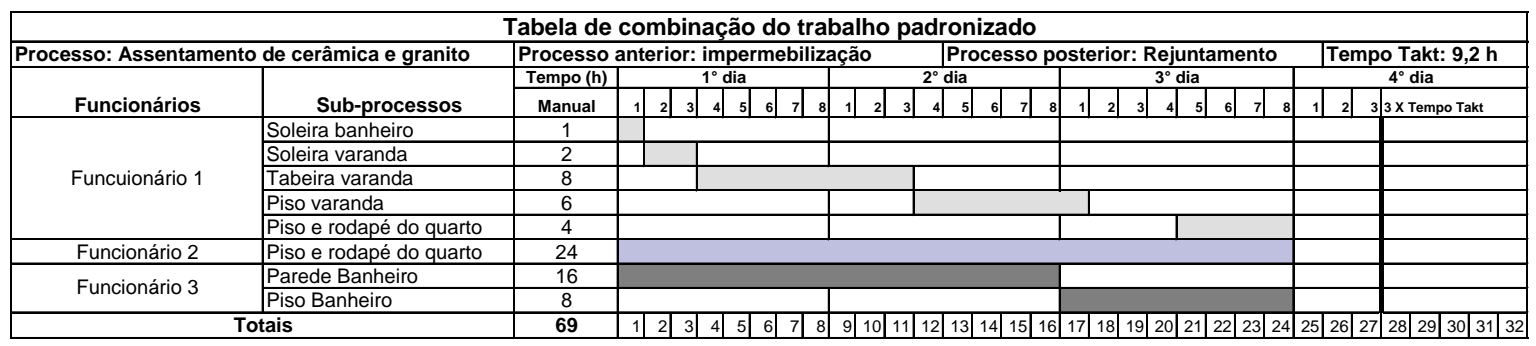

Figura 8 - Tabela de Trabalho Padronizado Combinado - Cerâmica

\section{Discussão dos resultados}

Para aplicação das ferramentas no contexto na construção civil, foram feitas as seguintes adaptações à proposta de Rother e Shook (1999) e Rother e Harris (2002):

(a) planejamento através da LB, antes da elaboração do MFV do estado atual, gerada a partir do cronograma acordado com o cliente, para definir ritmos de produção dos processos chave. Estes ritmos foram utilizados para a definição dos tempos takt dos processos. Em contraste com a indústria da manufatura, este tempo takt não é definido a partir da demanda externa, mas considerando períodos de tempo disponíveis para executar etapas da obra;

(b) elaboração de mapas de fluxo de valor atual e futuro por processo, como um desdobramento do MFV para toda a obra;

(c) diferentemente da aplicação do mapa em outros contextos, nos quais se utiliza como lote de produção uma peça, neste estudo o lote considerado foi de um apartamento; e (d) para elaboração do GBO, não se usou o conceito de elemento de trabalho mas grandes lotes de operações, como, por exemplo, execução do piso do banheiro. Isso foi necessário em função da do T/C elevado (24 horas trabalhadas).

Analisando-se a aplicação das ferramentas, constatou-se que o uso da LB teve uma contribuição importante na proposta, pois auxiliou a entender os principais fluxos das equipes, os ritmos dos principais processos, o tamanho do lote destes processos e os estoques em processo. Permite detectar facilmente a falta de balanceamento e sincronia entre as atividades, que é um dos passos iniciais para a implementação do fluxo contínuo.

Com relação ao $\mathrm{MFV}$, este foi utilizado inicialmente para mapear o fluxo de um produto, complementando a análise realizada por meio da LB. Através desta técnica, podem-se estimar algumas perdas, comparando-se o LTP e o TAV, e analisar a possibilidade de eliminar pontos de programação. A explicitação do desperdício que existe na produção, através da diferença entre o LTP e o TAV, mostrou-se de grande importância 
para discussão e proposição de melhorias com os gestores da obra.

A aplicação do mapeamento do fluxo de valor atual e futuro de processos de produção considerados como críticos foi eficaz para identificar desperdícios e propor um conjunto de melhorias. Neste sentido, o roteiro proposto por Rother e Shook (1999) contribuiu para estruturar a tomada de decisão referente à implementação de conceitos e ferramentas da ME. O uso da GBO permitiu distribuir grupos de operações entre os funcionários envolvidos na produção, visando obter um balanceamento das equipes. Foi proposta a utilização da Tabela de Trabalho Padronizado Combinado para planejar o trabalho das equipes de forma explícita e controlar os fluxos de trabalho.

$\mathrm{Na}$ discussão final, a diretoria da empresa compreendeu o grande potencial para implementação do fluxo contínuo. Porém, como a obra ainda enfrentava problemas relacionadas a falta de estabilidade básica, principalmente em relação ao fornecimento de materiais e de mão-deobra capacitada. Por esta razão, a empresa optou por priorizar a implementação do PCP hierarquizado, incluindo reuniões de médio e curto prazo, para prioritariamente se identificar e remover restrições.

\section{Estudo empírico 2}

\section{Diagnóstico do PCP}

No início do estudo, o planejamento da obra limitava-se a um cronograma detalhado, não existindo outros níveis formais de planejamento. Este plano era utilizado como referência para avaliar o avanço físico, sendo mensalmente produzido um gráfico comparando a produção prevista em relação à realizada. A empresa utilizava um sistema de informação ERP (Enterprise Resource Planning), no qual os dados referentes ao avanço físico eram inseridos. Mensalmente, existia na empresa uma reunião com todos os engenheiros e coordenadores de obra com o gerente de produção da regional, na qual eram apresentados os resultados das obras no período. Porém, tanto o cronograma como o plano de longo prazo inserido no ERP estavam desatualizados e não refletiam a realidade da obra.

Não havia um planejamento formal dos principais fluxos das equipes, porém informalmente existia um sequienciamento para a execução das casas, sendo a obra dividida entre dois sub-empreiteiros. Também não haviam sido definidos ritmos de produção dos processos já iniciados: cada subempreiteiro tinha um ritmo de trabalho diferente, contribuindo para o aumento da variabilidade em relação ao tempo de ciclo da execução desses processos. A 0 , na qual são apresentados os tempos de ciclo dos processos de radier, alvenaria inferior e primeira laje, ilustra esta variabilidade. Por exemplo, o radier foi executado, em média, em 4,5 dias, variando entre 4 e 11 dias. Os dados do tempo de ciclo foram coletados durante três meses, para todos os serviços executados neste período.

Após o diagnóstico, foram propostas ações de melhorias no PCP para aumentar a estabilidade, visando a criar condições iniciais para a implementação do fluxo contínuo. Essas ações foram baseadas no Sistema Last Planner.

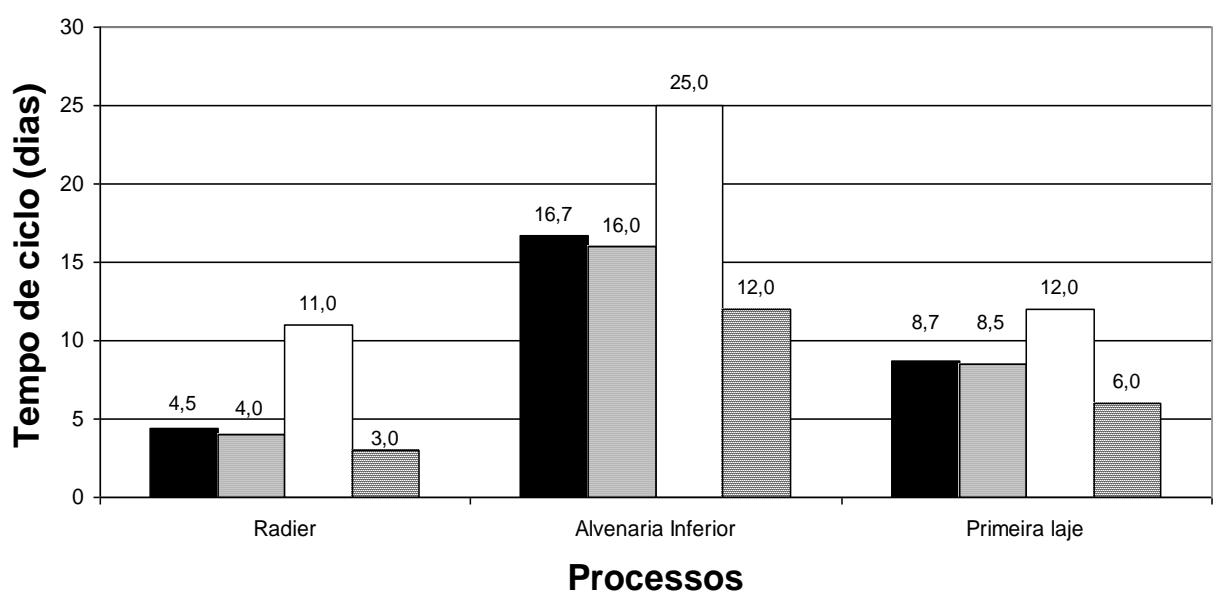

- Produção média $\square$ Produção Mediana $\square$ Produção Máxima

Figura 9 - Tempos de ciclo antes da implementação (por bloco de duas casas) 


\section{Implementação de melhorias}

Na 0 está apresentada a versão final da LB do empreendimento. Para o plano foi adotado como lote duas unidades-base e usou-se como fonte principal de informação o cronograma da obra e, também, os dados de duração e produtividade dos processos já iniciados. Na elaboração da LB foram também introduzidas algumas melhorias, como, por exemplo:

(a) buscou-se sincronizar, pelo menos parcialmente, os processos de radier, alvenaria inferior, primeira laje, alvenaria superior, e segunda laje, por meio do redimensionamento das equipes usando-se os dados de tempo de ciclo reais; e

(b) busca pela redução de estoques em processo

Porém, nota-se na 0 que ainda há muitas folgas entre processos, enquanto em alguns períodos existe sobrecarga de trabalho. Isso ocorria em função dos processos terem ritmos estimados diferentes e problemas relacionados à gestão de suprimentos.

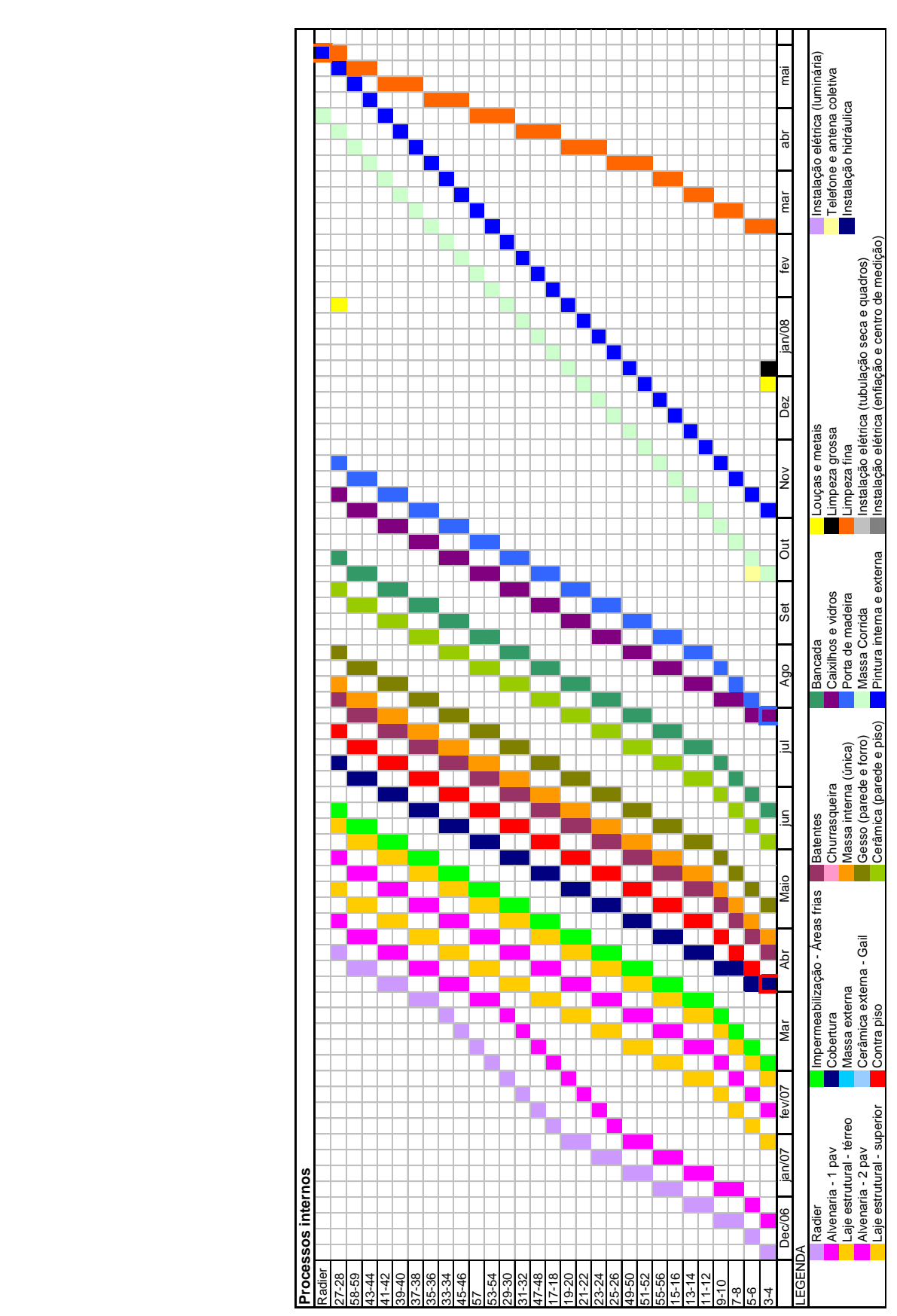

Figura 10 - LB da obra 
No planejamento em nível de médio prazo, propôsse um horizonte de tempo de três meses e replanejamento mensal. Porém, este plano foi realizado somente uma vez pela falta de disponibilidade de tempo da equipe da obra. No curto prazo foram realizadas reuniões semanais, que tinham a duração em torno de uma hora. A intervenção realizada foi bem sucedida no sentido de rotinizar e formalizar as reuniões de curto prazo, as quais sempre contavam com a participação dos representantes das equipes de produção.

Para avaliar a eficácia do planejamento foram utilizados os indicadores de PPC e as causas do não cumprimento destes pacotes. Também foi monitorado o tempo de ciclo de alguns processos. $\mathrm{Na} 0$ está apresentado o gráfico contendo o PPC ao longo do estudo. O PPC médio foi de $78 \%$, com desvio padrão de $15 \%$ e coeficiente de variabilidade de $19 \%$. Nota-se claramente uma tendência de melhoria e de estabilidade no indicador PPC, com exceção de duas semanas, nas quais ocorreram chuvas intensas na obra.

Com relação às causas do não cumprimento de planos, observaram-se que os maiores problemas foram referentes ao planejamento e aos suprimentos (0a). Dos problemas relacionados ao planejamento verificou-se que os maiores percentuais eram relacionados à equipe produzindo abaixo do planejado, à falta de mão de obra do empreiteiro, à falha na programação de tarefas e ao pacote de trabalho grande demais (0b). Com relação aos suprimentos, verificou-se que e $10 \%$ dos problemas se relacionavam com a falta de material. Ou seja, a maioria dos problemas era interna à empresa e poderiam ser reduzidos através de melhorias na própria implementação do PCP.

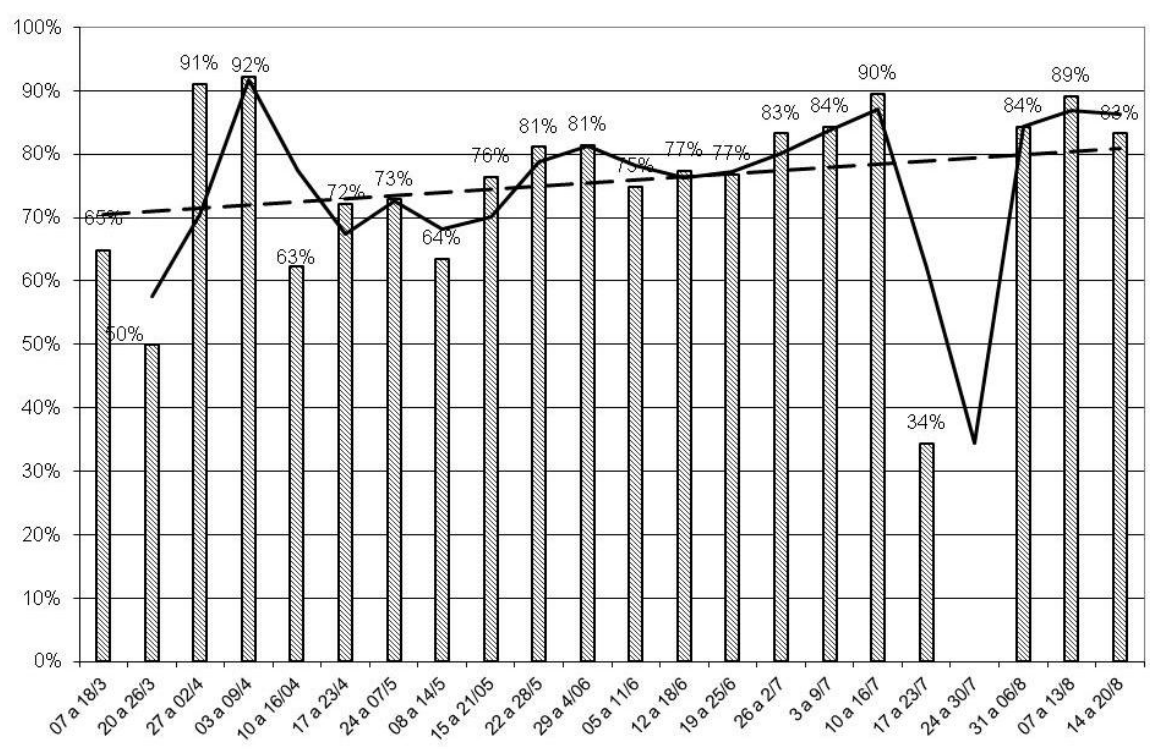

PPC - - Tendência 2 por Média Móvel (PPC)

Figura 11 - PPC da obra

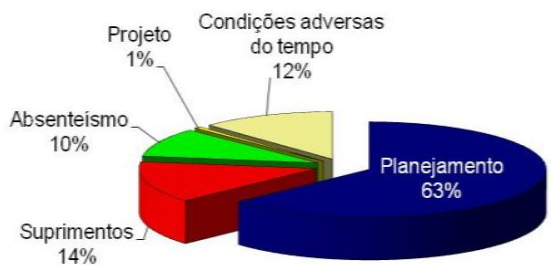

(a)

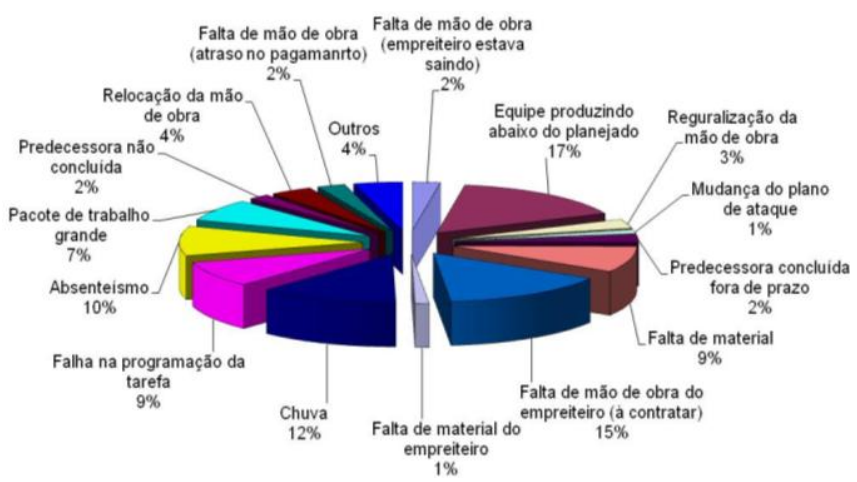

(b)

Figura 12 - Causas agrupadas e causas desdobradas dos não cumprimentos dos planos 
A 0 apresenta os tempos de ciclo dos principais processos após a implementação das melhorias no sistema de PCP. Houve uma redução tênue em alguns tempos de ciclo médios (por exemplo, radier, alvenaria inferior e primeira laje), embora ainda se observe uma elevada variabilidade em alguns processos. Isso ocorreu em função de falhas na própria implementação do PCP, principalmente em relação ao planejamento de médio, principal ferramenta do Last Planner em gerenciar os recursos.

\section{Discussão dos resultados}

Nesse estudo a estabilidade foi alcançada apenas parcialmente em parte em função de limitações na implementação do Last Planner. Uma das dificuldades para introduzir as mudanças no PCP foi o foco no controle através do sistema ERP. Neste sistema, não havia hierarquização de planos nem a explicitação dos ritmos dos principais processos. O longo tempo gasto por parte do gerente a obra em preencher informações no ERP representava um obstáculo à implementação de algumas melhorias propostas, tais como o planejamento de médio prazo, já que o mesmo alegava falta de tempo para as reuniões.

Além disto, embora houvesse na obra um esforço muito grande para disponibilizar os recursos em termos quantitativos, persistiam os problemas relativos à qualidade dos recursos, tais como capacitação da mão-de-obra e qualidade dos materiais. Isto se deve à pouca ênfase dada na implementação do Last Planner a ações que garantam a qualificação destes recursos - o tempo relativamente pequeno gasto na solução de problemas nas reuniões de curto e médio prazo não é suficiente para a gestão de fluxos a montante da produção.

Porém, apesar das limitações da implementação do Last Planner, este sistema trouxe alguns benefícios relacionados à gestão da obra, tais como maior comprometimento das equipes e melhor gerenciamento das interdependências entre as mesmas, o que é evidenciado pelo PPC relativamente alto (cerca de $80 \%$ ).

A principal conclusão deste estudo é o grande esforço necessário para alcançar a estabilidade como pré-condição para implementar fluxo contínuo. No contexto da construção civil, parece ser difícil atender a todas as condições iniciais sugeridas pela bibliografia para atingir a estabilidade básica. Por exemplo, o trabalho padronizado, sugerido como um dos requisitos por Smalley (2005) parece ser um dos resultados da implementação de fluxo contínuo e não um prérequisito para o mesmo. Ou seja, a redução dos tempos de ciclo e do tamanho do lote são melhorias que podem ser buscadas como parte da implementação do fluxo contínuo, a partir do uso das ferramentas GBO e TTPC.

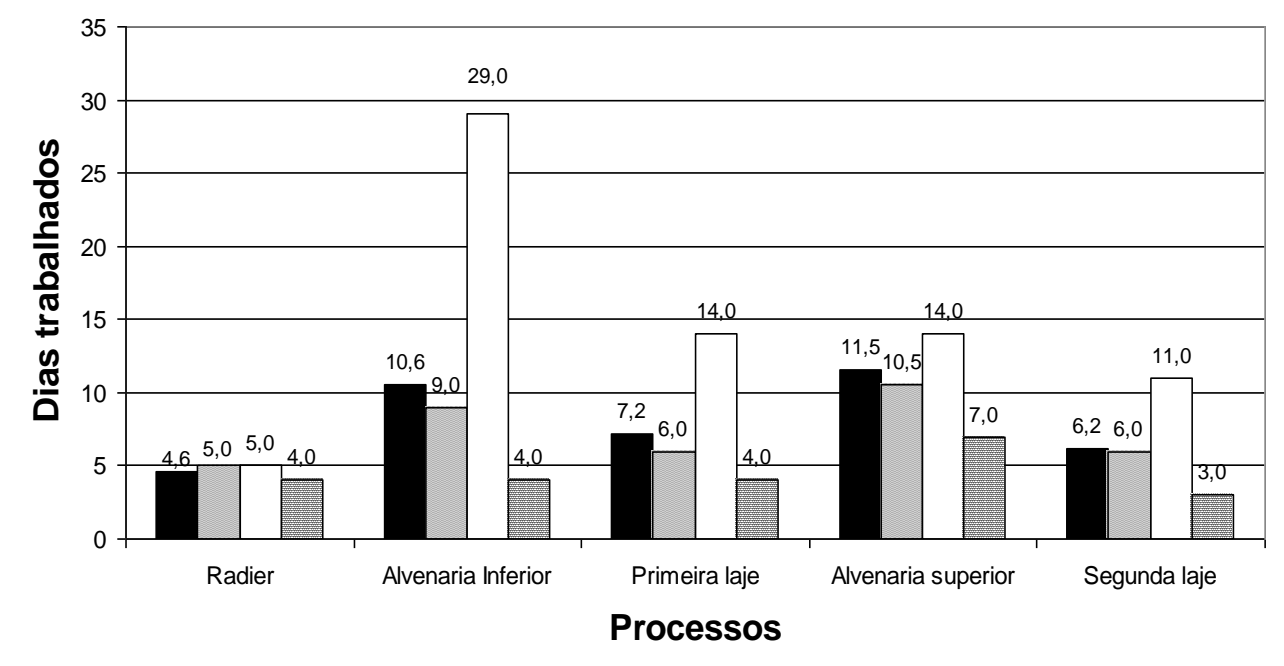

- Produção média $\square$ Produção Mediana $\square$ Produção Máxima घ Produção Mínima

Figura 13 - Tempos de ciclo dos processos ao longo da implementação 


\section{Diretrizes propostas}

As diretrizes para a implementação do fluxo contínuo estão vinculadas a quatro etapas:
(a) diagnóstico;
(b) estabelecimento de condições iniciais;
(c) planejamento do fluxo de valor, e
(d) controle.

A seguir estas etapas serão detalhadas, salientando-se a simultaneidade que ocorre entre elas.

\section{Diagnóstico}

$\mathrm{Na}$ etapa de diagnóstico, são necessárias informações sobre o processo de planejamento e controle existente, e os principais problemas enfrentados pela obra, tais como a existência de estoques, falhas de projeto e dificuldades com suprimentos. Este diagnóstico deve envolver uma análise qualitativa, a partir de entrevistas com funcionários da empresa envolvidos no PCP e visitas à obra, mas deve também ser baseado na aplicação sistemática de ferramentas e indicadores de forma a gerar dados quantitativos, entre as quais o MFV inicial.

\section{Estabelecimento de condições iniciais}

Simultaneamente à realização do diagnóstico, deve-se buscar o estabelecimento das condições mínimas necessárias na obra para iniciar a implementação do fluxo contínuo, através de melhorias no sistema de planejamento e controle da produção. As melhorias sugeridas são baseadas no Sistema Last Planner, principalmente no sentido de hierarquizar este processo de planejamento nos seguintes níveis:

(a) longo prazo: propõe-se a utilização da LB, cuja a elaboração deve levar em conta a redução dos estoques em processo, sincronia entre processos, redução dos lotes e continuidade no trabalho de equipes;

(b) médio prazo: através da identificação e remoção sistemática de restrições, busca-se aumentar a disponibilidade dos recursos necessários para a execução das atividades na obra; e

(c) curto prazo: este nível cumpre um papel importante nas etapas de diagnóstico e criação das condições iniciais.

No diagnóstico, o indicador de eficácia do planejamento (PPC) e a identificação das causas do não cumprimento dos pacotes podem auxiliar na identificação de problemas na obra. Já em relação às condições iniciais, nas reuniões semanais de planejamento, pode-se gerenciar os compromissos com as diferentes equipes envolvidas e gerenciar as interdependências entre os processos.

\section{Planejamento do fluxo de valor}

A terceira etapa envolve o planejamento do fluxo de valor, em diferentes níveis, desde a obra como um todo, passando pelo fluxo de valor das unidades repetitivas, definidas no planejamento de longo prazo, assim como o desdobramento deste em processos e operações específicas. Na 0 são apresentados os níveis de análise propostos para empreendimentos da construção civil.

Com base nas informações geradas pela LB, podese elaborar o primeiro MFV para a unidade repetitiva definida no planejamento de longo prazo. O cálculo da quantidade de estoques em processo pode ser feito a partir de uma unidade intermediária da LB. Esse mapa fornece uma informação bastante relevando para o diagnóstico, através da explicitação dos desperdícios (diferença entre lead time e tempo de processamento).

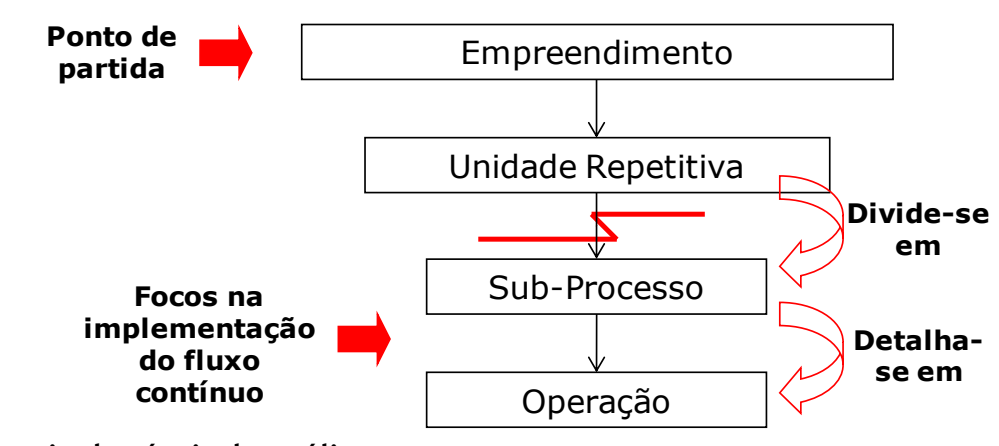

Figura 14 - Hierarquia de níveis de análise 
Ao se passar as informações da LB para o MFV, muda-se o nível de análise, do fluxo de valor do empreendimento como um todo para o fluxo de uma unidade repetitiva. No presente trabalho propõe-se o uso sistemático das três ferramentas da Mentalidade Enxuta (MFV, GBO e TTPC) para grupos de processos que podem ser executados em fluxo contínuo. Ou seja, propõe-se a implementação de fluxo contínuo não para toda a obra, mas de uma forma gradual em grupos de processos, sincronizando seus ritmos e reduzindo o estoque em processo entre estes.

Para elaboração do MFV do estado futuro pode-se usar o roteiro proposto por Rother e Shook (1999), que estabelecem uma estrutura para a tomada de decisão referente à implementação de conceitos e ferramentas da ME, dentro de uma visão integrada.

Em relação à aplicação do GBO, a unidade de análise nessa fase passa a ser a operação, ou seja, o fluxo humano temporal e espacial centrado no trabalhador. É importante que se tenham dados da própria obra, considerando as peculiaridades da mesma. Além disso, existem duas questões a serem observadas na implementação do GBO: o nível de detalhe de elementos do trabalho, que deve ser o menos agregado possível e a possibilidades de uso de funcionários multifuncionais.

Em relação à TTPC, sugere-se a participação efetiva dos funcionários na sua configuração final, principalmente no que se refere ao seqüenciamento das atividades por funcionário e ao tempo planejado para executar cada trabalho. Deve-se usar a diferença entre o tempo de ciclo e tempo takt para a resolução de problemas que, por ventura, ocorram nesse intervalo de tempo.

\section{Controle}

Finalmente, a etapa de controle está relacionada ao monitoramento dos resultados e realização das ações corretivas necessárias para que as metas do empreendimento sejam atingidas. Nesta etapa existe a necessidade de indicadores de desempenho e mecanismos que permitam a retro-alimentação eficaz dos mesmos. Além dos indicadores tradicionais de PCP, deve-se também empregar outros indicadores que possuem ligação direta com os conceitos e princípios da ME, entre os quais podem ser destacados os seguintes:

(a) percentagem do tempo gasto em atividades que agregam valor para cada unidade repetitiva;

(b) quantidade de estoques em processo;

(c) tempo de ciclo da unidade repetitiva; e (d) indicadores de aderência à seqüência e ao lote definidos.

\section{Conclusões}

O trabalho teve como objetivo geral propor diretrizes para a implementação de fluxo contínuo na construção civil, com base em dois estudos empíricos. A principal contribuição do estudo 1, foi a adaptação do método proposto por Rother e Harris (2002) para a construção civil. É importante salientar o uso da LB como ponto de partida para a elaboração do MFV e cálculo do tempo takt. Chama-se a atenção para a adaptação efetuada nas ferramentas GBO e a TTPC, que considerou grupos agregados de operações, em oposição ao elemento de trabalho. Ao fim do estudo, constatouse a necessidade de se ter condições iniciais mínimas para iniciar a implementação de fluxo contínuo em obras.

No estudo 2 investigaram-se as condições iniciais para implementação do fluxo contínuo em obras de edificações, constatando-se que a estabilidade básica é uma condição de implementação bastante complexa, podendo ser obtida apenas de forma gradativa ao longo do processo de implementação de fluxo contínuo. Em função desta constatação, neste estudo o foco da implementação foi a introdução de melhorias no PCP. Ao fim do estudo, obteve-se sucesso na criação de condições iniciais para a implementação do fluxo contínuo, principalmente por se ter implementado na obra uma sistemática tomada de decisões participativas, tanto no nível tático quanto no operacional. Ao fim dos estudos empíricos foram propostas as diretrizes para implementação do fluxo contínuo em obras de edificação. Considerou-se que o processo de implementação possui quatro etapas: diagnóstico, criação das condições iniciais, planejamento e controle.

A partir do estudo realizado, pode-se apontar algumas oportunidades para desenvolvimento de futuros trabalhos, principalmente no que se refere à aplicação das diretrizes de implementação em obras de edificação. Por exemplo, poderia ser investigado o uso de protótipos físicos ou virtuais para refinar os padrões de processo e buscar o balanceamento e a sincronização entre as equipes. Há também necessidade de refinar alguns conceitos que têm origem na manufatura, de forma a adaptá-los ao contexto da construção civil, tais como estabilidade básica e trabalho padronizado. 


\section{Referências bibliográficas}

ALVAREZ, R.; ANTUNES JÚNIOR., J. A. V. Takt-Time: conceitos e contextualização dentro do Sistema Toyota de Produção. Revista Gestão \& Produção, v. 8, n. 1, p. 1-18, abr. 2001.

ARDITI, D.; ALBULAK, M. Z. Line-of-Balance Scheduling in Pavement Construction. Journal of Construction Engineering and Management, v. 112, n. 3, p. 411-424, set. 1986.

BALLARD, G. Lookahead Planning: the missing link in production control. In: ANNUAL CONFERENCE OF THE INTERNATIONAL GROUP FOR LEAN CONSTRUCTION, 5., Gold Coast, Australia, 1997. Proceedings... Gold Coast: Griffith University, 1997. p. 13-25.

BALLARD, G.; HOWELL, G. Shielding Production: an essential step in production control. Journal of Construction Engineering and Management, v. 124, n 1, p. 11-17, jan./fev. 1998.

BLACK, J. T. O Projeto da Fábrica com Futuro. Porto Alegre: Bookman, 1998.

BULHÕES, I. R.; FORMOSO, C. T. Desenvolvimento e Aplicação de Ferramentas Gráficas para Obras de Habitação de Interesse Social. In: CONFERÊNCIA LATINOAMERICANA DE CONSTRUÇÃO SUSTENTÁVEL, São Paulo, 2004; ENCONTRO NACIONAL DE TECNOLOGIA DO AMBIENTE CONSTRUÍDO, 10., São Paulo, 2004. Anais... São Paulo: ANTAC, 2004.

HOPP, W. J.; SPEARMAN, M. L. Factory Physics: foundations of manufacturing management. Boston: Irwin Mc Graw-Hill, 1996. $668 \mathrm{p}$.

KOSKELA, L. Application of the New Production Philosophy to Construction. Stanford: Stanford University, 1992. (Technical Report, 72).

KOSKELA, L. An Exploration Towards a Production Theory and Its Application to Construction. Espoo, Finlândia: VTT, 2000. (VTT Publications, 408).

LEAN INSTITUTE BRASIL. Léxico Lean: glossário ilustrado para praticantes do pensamento lean. Tradução de Lean Institute Brasil. São Paulo: Lean Institute Brasil, 2003.

LIKER, J. K. The Toyota Way. 14 Management Principles From the World's Greatest Manufacturer. New York: McGraw-Hill, 2004. $330 \mathrm{p}$.
LIKER, J. K.; MEIER, D. O Modelo Toyota: manual de aplicação. Porto Alegre, Bookman, 2007. $432 \mathrm{p}$.

MONDEN, Y. Toyota Production System: an integrated approach to just-in-time. London: Chapman \& Hall, 1993. 423 p.

PRADO, R. L. Aplicação e Acompanhamento da Programação de Obras em Edifícios de Múltiplos Pavimentos Utilizando a Técnica da Linha de Balanço. 140 f. Florianópolis, 2002. Dissertação (Mestrado em Engenharia Civil) Escola de Engenharia, Universidade Federal de Santa Catarina, Florianópolis, 2002.

ROTHER, M.; HARRIS, R. Criando o Fluxo Contínuo: um guia de ação para gerentes, engenheiros e associados da produção. São Paulo: Lean Institute Brasil, 2002.

ROTHER, M.; SHOOK, J. Aprendendo a Enxergar: mapeando o fluxo de valor para agregar valor e eliminar o desperdício. São Paulo: Lean Institute Brasil, 1999.

SAMANIEGO, C. A. Princípios e Ferramentas do Lean Thinking na Estabilização e Padronização Básica de Elementos de Trabalho: subsídios para implantação no processo de fabricação de telhas de concreto pré-fabricados. 115 f. Campinas, São Paulo, 2007. Dissertação Escola de Engenharia, Faculdade de Engenharia Civil, Arquitetura e Urbanismo, Universidade Estadual de Campinas, Campinas, 2007.

SANTOS, A. Application of Flow Principles in the Production 'Management of Construction Sites. Thesis (Ph.D.) - School of Construction and Property Management, University of Salford, 1999.

SCHRAMM, F. K.; RODRIGUES, A. A.; FORMOSO, C. T. The Role of Production System Design in the Management of Complex Projects. In: ANNUAL CONFERENCE OF THE INTERNATIONAL GROUP FOR LEAN CONSTRUCTION, 14., Santiago, Chile, 2006. Proceedings... Santiago: Pontificia Universidad Catolica, IGLC, 2006.

SEPPÄNEN, O.; KANKAINEN, J. Empirical Research on Deviations in Production and Current State of Project Control. In: ANNUAL CONFERENCE OF THE INTERNATIONAL GROUP FOR LEAN CONSTRUCTION, 12., Elsinore, Denmark, 2004. Proceedings... Elsinore: IGLC, 2004.

SMALLEY, A. The Starting Point for Lean Manufacturing: achieving basic stability. Management Services, v. 49, n. 4, p. 8-12, winter 2005. 
SPEAR, S; BOWEN, H. K. Decoding the DNA of the Toyota Production System. Harvard Business Review, Boston, v 77, n. 5, p. 96-106, set./out. 1999.

TAKAHASHI, Y.; OSADA, T. TPM/MPT: manutenção produtiva total. 3 ed. São Paulo: Instituto IMAM, 1993. 332 p.
THIOLLENT, M. Metodologia da PesquisaAção. 14. ed. São Paulo: Cortez, 2005. 132 p.

WOMACK, J. P.; JONES D. T. A Mentalidade

Enxuta nas empresas: elimine o desperdício e crie riqueza. Tradução de Ana Beatriz Rodrigues e Priscila Martins Celeste. 5. ed. Rio de Janeiro: campus, 1996.

Revista Ambiente Construído Associação Nacional de Tecnologia do Ambiente Construído Av. Osvaldo Aranha, $99-3^{\circ}$ andar, Centro Porto Alegre - RS - Brasil CEP $90035-190$

Telefone: +55 (51) 3308-4084 Fax: +55 (51) 3308-4054 www.seer.ufrgs.br/ambienteconstruido E-mail: ambienteconstruido@ufrgs.br 